\title{
The Effect of Teaching Paragraph Structure Rules on Iranian Intermediate EFL Learners' Reading Comprehension Ability
}

\author{
Amir Marzban \\ English Language Department, Qaemshahr Branch, Islamic Azad University, Qaemshahr, Iran \\ Azadeh Adibi (Corresponding Author) \\ English Language Department, Science and Research Branch, Islamic Azad University, Mazandaran, Iran
}

\begin{abstract}
Reading is useful for language acquisition" (Harmer, 2007, p.99) and more or less it affects different aspects of the learner's life. Reading and writing are two literacy skills which are interconnected, therefore, to become a good reader an understanding of the writing styles is needed. The current research focused on the interrelationship between two literacy skills; reading and writing. According to Rosenblatt's (1988) "transactions theory" which concentrates on the similarities between reading and writing and also, the Harwood's (2002) "lexical approach" which concerns the significance of genre analysis on facilitating the teaching process, the researcher conducted the study on instructing different writing genre characteristics to the learners in reading classes at the paragraph level and its effectiveness on improving the reading comprehension ability of the Iranian intermediate EFL learners was investigated. In order to implement the current research, two groups of homogenized intermediate participants were selected, one as the experimental and the other as the control group and after exercising the treatment, the mean scores of the extracted data from both groups were compared by running independent sample t-test and finally, the study came to this conclusion that these two kinds of treatments had significant difference and the students who were taught reading strategies accompanied by paragraph writing structure rules outperformed the control group which just received common reading strategies.
\end{abstract}

Index Terms - reading comprehension ability, paragraph structure rules, writing genres

\section{INTRODUCTION}

Reading comprehension ability has been the focus of research among most language teaching scholars. Reading skill is considered to be the most critical and essential ability for students in both classroom settings and real life environments (Carrell, 1989, \& Grabe and Stoller, 2002). Therefore, one of the many challenges in learning a new language is learning to comprehend the reading texts of that language. "Reading is useful for language acquisition" (Harmer, 2007, p.99) and more or less it affects different aspects of the learner's life.

There exist many strategies that can be utilized in the process of reading comprehension. Skillful readers do not employ just one reading strategy to comprehend the reading texts; they hold a choice of strategies and utilize distinct strategies at various places in a passage. They shift strategies while the reading text necessitates (e.g., Brown et al., 1983; Levin \& Pressley, 1981).These reading comprehension strategies must be modeled, learned, repeated and reinforced for a reader to develop from a novice reader to a proficient one. The current research is an attempt to introduce a newly practiced reading strategy which made use of writing rules.

Since reading and writing are two literacy skills which are interconnected, having mastery over these skills is mastery on half of the language abilities. To become a good reader an understanding of the writing styles is needed. There is no doubt that reading and writing are the mutual interactive skills. There is a close relationship between reading and writing format. As cited in Moreillon (2007, p.101) "Reading and writing are the two sides of the literacy coin; one cannot and should not be separated from the other". According to Rosenblatt (1988, p.2), "The relationship between reading and writing signals that these two kinds of linguistic activities are closely connected". Therefore it seems that by teaching writing rules or genres, the process of comprehending reading texts will also be facilitated. Gee (2008, p.45) stated that "literacy practices are almost always fully integrated. The good readers are also good writers", as also Thaole (2011) believes, the more they read, the better their writing ability is, and the more skillful in using words in writing is. But is it true from the other side? In the current research, the researcher tried to examine if being aware of the paragraph writing structures or genres can affect the reading comprehension of the learners.

Every kind of text of reading is composed of paragraphs, in other words paragraphs are building blocks of a text. They begin the process of tying individual ideas together to explain a more complex thought. They mostly appear in a variety of patterns of organization or writing genres; descriptive, process, narrative, comparison and contrast, 
classification, definition, and cause and effect. Therefore; in the current study, the effectiveness of having the knowledge of writing genres on reading comprehension ability was examined at paragraph level.

According to Nation (2009) using a framework based on principles of teaching and learning will guide teachers provide a wealth of suggestions for helping learners at all proficiency levels develop their reading and writing skills. Hence the current research tried to introduce a framework of teaching reading comprehension made by writing structure rules. In order to teach the rules of different paragraph writing structures to the participants, the graphic organizers of different paragraph genres were utilized and also these instructions were accompanied by teaching most commonly used reading strategies. In other words, the reading and writing syllabuses were integrated together in every session of instruction.

\section{REVIEW OF THE RELATED LITERATURE}

Since any research project and any teaching method rely on some assumption and theories, the author feels the need to scrutinize theories underlying the current practice.

\section{A. Theoretical Background}

\section{Transactional theory}

Some scholars stated that there is a mutual relationship between reading and writing skills, or in other words they believed that these two literacy skills are integrated. Recently diverse studies regarding the connection between the two literacy skills are in progress. Rosenblatt (1988) presented a coherent theoretical approach to interrelationship of the reading and writing processes.

Rosenblatt (1988) explained the term transactional theory. The transactional theory presents the interrelationship between reading and writing processes. Reading and writing are necessarily involved with texts. Therefore, both miss the nonverbal tending towards communication which exists in listening and speaking activities. He stated that reading and writing are clearly different in that the writer initiates with a blank page and tries to develop a text, when the reader initiates with the previously written or published paper and must fetch the meaning.

Again he believed that reading and writing processes are integrated together. Both reader and writer are involved in composing symbolic structures of meaning in a circular transaction with the text, whether the verbal signals are already presented or developed by another person, like the reader, or being created by the writer. They pursue the same models of thought, and employ the same linguistic habits. Both processes rely on the person's experiences with language in specific life positions. He also mentioned that both reader and writer are trying to create new linkages and new organic states by depicting previous linkage of signs, signifiers, and organic states. Both reader and writer originate a model, rule, or aim, however dim or explicit that leads the discriminating concern and the synthesizing, organizing activities which finally establish meaning. Furthermore every reading and writing work can be interpreted as a continuum.

\section{Genre Approach}

Genre-based approaches which focus on the realizing and development of favorite genres of texts have been as a major tendency in English language teaching in the new century. The writing genre is a formulaic structure made up of fixed patterns of word or ideas with a specific communicative purpose. Genre analysis has become significant in interpreting the discourse of the fields of study and the workplace, relatively structured borders of sociable interaction. According to Berkenkotter and Huckin (1995) "Genres are the intellectual scaffolds on which community-based knowledge is constructing. Genres offer an important way of framing and categorizing texts which assists comprehension. Genres provide an important frame of reference which help both learners and readers to identify, understand and interpret texts" (p.24). Gledhill (1995) noted that genres may serve as a way of preventing a text from fading out into individuality and incomprehensibility. As stated in Rezvani, Aqdam, \& Saeidi (2012), the recognition of a text as piece of a genre enables less proficient readers to determine whether it is probable to attract them.

According to Harwood (2002) there have newly been several corpus-based studies which prove that substantial differences are from genre to genre. These corpus data, which expose the variety of linguistic features and rhetorical structures among genre, have reinforced the introduction of the genre approach in writing. The genre approach assumes that readers have definite expectations about what a text is like, that is a part of a genre and writer should try to pursue these principles to help readers. Genre knowledge conducts genre readers towards appropriate beliefs, and feelings about a text which are crucial in making meaning. According to Hyland (2004) frames establish the scaffolding which guides language learners to pass through spoken to written language use. And also Livingstone (1994) stated that different genres define different frameworks which provide a negotiation between the text and the reader that prepares definite beliefs for each side of the communication.

\section{B. Previous Studies}

Various studies have concentrated on the interrelationship between the two literacy skills; reading and writing. This issue can be examined from two directions, one from the effectiveness of improving reading comprehension ability on writing ability and the other from the effectiveness of improving writing ability on reading comprehension ability. It is believed that one facilitates the other but here our center of attention is especially from writing ability to reading comprehension ability, although it is not a unidirectional theory and it also can be seen from the other side, but it is 
skipped in this research. Similar researches to the current study are reviewed in the following paragraphs according to their relativeness to the point of view of the current research.

Goen and Tropp (2003) tried to integrate the reading and writing courses and looked at this issue from both directions, learning to write as readers and read as writers. They linked instruction in reading with instruction in writing because they believed that the process of reading and writing are closely linked. This integrated program was done for one year (two semesters) at the San Francisco State University (SFSU) campus in a context which its participants were native English speakers or the immigrants who had a reasonable knowledge of English. This research included two groups, the control group with 204 students and the integrated group with 136 students. In measuring the amount of development that student had based on the integrated program instruction, the researchers made use of standardized reading tests, scored portfolios of student writing, self-assessments of students. The students' self-assessments on the reading and portfolio writing showed that the integrated course is having a positive influence on students' literacy development and on their confidence and satisfaction as learners. Making use of the portfolios and self-assessments suggests that they are able to develop an authoritative and confident position in their writing. It makes internalized readers that can guide their own writing process. Finally they came to this conclusion that students in the integrated program scored higher than the control group.

Culp and Spann (1987) studied the influence of improving writing skill on reading comprehension ability. They performed their research on forty students of university of south Alabama, twenty one students in experimental group and nineteen in control group. They administered Nelson Denny Reading Test as pre-test and post-test. The students received a ten week instruction that was two periods in every week. Both groups had the same instructor and the same reading material and also they had extra readings such as selected articles, essays, short stories, and novels. Instruction varied only in the use of writing components for the experimental group. The experimental group wrote in the class at least once a week and the modes of writing practiced were dictation, paraphrase, précis - "abstract or summery which captures the essence of a selection within a required word limit" Hood(1967) as cited in (Culp\& Spann, 1987, p.285)-, and expressive -"writing close to the self, having the characteristics of informal talk and revealing as much about the writer as about the topic" Britton, et al.(1977) as cited in(Culp \& Spann, 1987, p.285)- for the material they read. Some of the assignments included one or two modes. At last the analysis of the covariance (ANCOVA) was used to compare the performance of the two groups on the post- test which indicated a significant difference between the two groups. The findings of this research revealed that writing has a positive effect on reading comprehension ability.

Graham \& Hebert (2010) introduced evidences for how improvement in writing can affect reading. They concerned the basic literacy problems of American adolescents that cause financial and social costs for individuals and also for the country and for removing this problem they did this research on students in grade 1 to 12 studying at schools. They did this study to discover effective practical techniques for reading comprehension improvement. They made use of both norm-referenced published standardized tests and researcher designed tests in order to assess the reading comprehension. Their research had three phases which are related to the following questions:

1. Does writing about material students read enhance their reading comprehension?

2. Does teaching writing strengthen students' reading skills?

3. Does increasing how much students write improve how well they read?" (Graham \& Hebert, 2010, p.4)

For answering the above questions the researchers examined these techniques through a quasi experimental design. The control condition in most of these studies was reading or reading instruction. Their first technique was to make students write about the texts they read. Therefore, the students' comprehension of science, social studies, and language texts is improved when they tried to write about the reading materials, particularly by responding to a text by writing (writing individual experiences related to the reading text or writing an analysis of the characters in a novel-extended writing), writing summaries of the text, writing notes about a text, and answering questions about a text in writing, or creating and answering written questions about a text. Examining each of these items separately on experimental groups showed the following results.

The evidence proved that having students write about the text they read enhanced their reading comprehension abilities. The review of the data showed that extended writing has a strong and consistently positive effect on reading comprehension. Moreover writing summaries about a text proved to be better than simply reading it, reading and rereading it, and receiving reading instruction. In addition, taking notes about text proved to be better than just reading. And also locating main ideas in a text, generating or responding to questions in writing, and then answering them in writing form had positive effect on improving the reading comprehension of students when compared to just reading simply or receiving reading instruction.

The second technique was to teach students the writing skills and processes that lead in creating text. This includes teaching the process of writing paragraph or sentence construction skills, teaching spelling and sentence construction skills, and teaching spelling skills. Examining each of them on experimental groups, proved the following results. Writing instruction did in fact show a positive effect on reading comprehension. The practice of putting smaller units of writing together in order to create more complex ones-from letters to words or words to sentences had a strong and consistent impact on improving students' reading fluency. Spelling instruction had a moderate and consistent impact on improving students' word reading skills. 
The third technique was to increase how much student write; students' reading comprehension is improved by increasing the times that they create their own texts. The strategies for extending the amount of writing in the studies reviewed included : "writing about self-selected topics or topics chosen in collaboration with peers, setting aside fifteen extra minutes a day for sustained writing, using the Internet to write to pen pals, writing journal entries about daily experiences, interacting with others using a dialogue journal, and writing short passages using inference words "(p.20).The outcomes showed that increasing the amount of times that the students write, in reality makes their reading ability better.

Findings of Graham and Hebert's (2010) study showed that "having students write about texts they read, explicitly teaching writing skills and processes, and having students write more improve reading skills and comprehension."(p.9)

\section{Statement of the Problem}

In a world which is overwhelmed by information, and available information is increasing in every second, the ability to read and comprehend the written texts can be seen as a prominent issue. All people should be able to read simple forms, interpret advertisements, study newspapers, and employ primal reading skills in their job and everyday lives when necessary. Some portion of these people need to comprehend new conceptual information from texts at much higher levels, combining and interpreting new information from various texts, reviewing data critically in texts and utilizing their comprehension abilities to understand texts. According to Grabe (2009), general literacy is an ideal goal that is an ongoing priority among many organizations around the world, and attempts need to be made to reduce illiteracy levels. Therefore comprehending the texts is a challenging activity in daily life of everyone in the modern globe.

Most of the language teachers and curriculum developers are attempting to enhance the learners' reading comprehension ability. During these years there have been numerous endeavors to discover instructional practices that improve learner's literacy skills, particularly the reading skill. They are studying and examining the most practical research based principles to improve their students reading comprehension ability. So it is a difficult and problematic duty over the shoulders of the instructors and curriculum developers to discover the worthiest strategy in teaching reading which enhances the comprehension.

Language teaching researchers were trying to identify the most effective instructional practice for improving reading comprehension. According to Graham \& Herbert, "One often-overlooked tool for improving students" reading, as well as their learning from text, is writing" (2010, p.4). Since writing and reading are two interconnected literacy skills, scholars often recommend writing as a device for improving reading comprehension. And because of the lack of research in this area, the current researcher felt the need to conduct a study based on teaching writing rules and investigating its effectiveness on reading comprehension ability.

\section{Research Question}

In order to understand the effectiveness of teaching paragraph structure rules on the reading comprehension ability of Iranian Intermediate EFL learners, the following question should be answered:

- Do teaching paragraph structure rules have any effect on the reading comprehension ability of Iranian Intermediate EFL learners?

\section{E. Research Null Hypothesis}

For answering the research question the current hypothesis is suggested by the researcher:

- Teaching paragraph structure rules has no effect on the reading comprehension ability of Iranian Intermediate EFL learners.

\section{Methodology}

The main purpose of the current study was to find another practical way for improving learners' reading comprehension ability in English language. This study set out to investigate the effect of teaching different paragraph structure rules on reading comprehension ability of Iranian intermediate EFL learners. Therefore, reading comprehension is considered as independent variable. Moreover, the researcher selected seven different paragraph structure rules or writing genres at paragraph level based on their application in most English language texts as a reading strategy, which was the independent variable of the study, to strengthen the participants' knowledge of writing rules and applied this as a strategy for improving reading comprehension ability.

\section{A. Participants}

The participants of this study were sixty homogenous EFL learners who have been selected from 117 volunteers of participating in the study which were gathered by spreading out advertisement in some educational places such as libraries, high-schools, universities and language institutes in Sari. They all were given Nelson proficiency test A4 (Fowler \& Coe, 1978) and the retrieved scores of the test were statistically analyzed and those volunteers whose scores fell within the range of one standard deviation below and above the mean were selected as the participants. They were at the range of 17 to 31 years old, the first language of all volunteers was Persian and both male and female genders participated in this study. 
The population of this study consisted of male and female EFL learners with the age of 17 to 31 who were studying English at different institutes, high-schools, universities in different cities in Iran. The researcher carried out this research at Hoonam Language Academy in Sari city at Mazandaran province of Iran. Based on the way of gathering the participants, the sampling for this study is convenience sampling.

\section{B. Instrumentations}

In the current study, different instruments were used for collecting the needed data. They included a standardized general language test, Nelson proficiency test A4 (Fowler \& Coe, 1978), a researcher made pre/post-test of reading. They are all described below.

\section{Nelson Proficiency Test}

Nelson proficiency test A4, contained 25 multiple choice items with four choices in each item was used as a standardized test of measuring the proficiency level of the learners. Before administering the Nelson proficiency test it was validated by the researcher and its reliability checked by piloting the test with thirty intermediate EFL learners and the Cronbach's Alpha measure of internal consistency showed an estimate of '.83', which indicated a high level of internal consistency for using in this (Iranian) context.

\section{Pre/Post-test of Reading Comprehension}

A multiple choice test, containing four passages with 36 items, was designed by the researcher as the pre/post-test of reading comprehension for intermediate level students. The researcher used this test to measure the participants' reading comprehension development before and after the treatment. Before using the test its validity was checked by the researcher and also it was piloted with thirty intermediate EFL learners and its reliability was measured by Cronbach's Alpha measure of internal consistency which provided an estimate of ' .90 ', which indicated a high level of consistency. It should be noted that the same test of reading was used as pre/post-test of reading.

\section{Procedure}

This research study was carried out over a five-week period of time. The investigation began on April 21, 2013 and completed on May 26, 2013.It comprised fourteen sessions. It began with administrating the Nelson proficiency test A4 (Fowler \& Coe, 1978) and selecting sixty homogenous intermediate EFL learners as participants. Then these people were randomly assigned into two groups of thirty, one as control and the other as experimental group. Afterwards, the pre-test of reading were given to both group members and two sets of scores were collected.

After randomly assigning the sixty selected participants through their Nelson Proficiency scores, the researcher felt the need to assure the homogeneity of the participants and also to confirm that both groups do not have significant difference at the starting point. Therefore, their scores at pre-test of reading on both experimental and control groups were compared by Independent Sample T-test and the result is shown in "Table 1". It should also be mentioned that before running the Independent Sample T-test, the normality of these two sets of scores was checked by running 'Kolmogorov-Smirnov' test of normality.

TABLE 1:

INDEPENDENT SAMPLE T-TEST FOR PRE-TEST SCORES TABLE

\begin{tabular}{|l|l|l|l|l|}
\hline & Levene's Test & Mean Difference & T & Sig. (2-tailed) \\
\hline Gain Score & .466 & -.06667 & -.058 & .954 \\
\hline
\end{tabular}

Since, the Sig of the Levene's test is '.466' and it is greater than '.05' which is the cut-off point, therefore, both experimental and control groups had equal variances at pre-test and also the sig of the T-test for equality of the mean is '.954' and greater that '.05' that shows the control and experimental groups did not have significant difference and it was concluded that the two groups were the same at the beginning.

Then the treatment process started, as explicitly stated in the following parts. The elapsed time for both groups was the same and the teacher of the both groups was the researcher herself.

\section{The Treatment Process for Experimental Group}

The main purpose of this research was to investigate the effect of teaching different writing genres at paragraph level on the reading comprehension ability of the EFL learners and this technique was implemented in the experimental group. For teaching different paragraph genres, the current researcher limited the treatment to some specific and more useable genres and also employed graphic organizers to clarify the position of every text element and to find a scaffold for each kind of genre.

As stated in Cochrane (2010), graphic organizers are extremely useful when modeling or introducing new concepts or text types as they allow the teacher to break the topic down into parts that can be taught and analyzed in greater detail to promote a deeper understanding. And also they are mostly used by writers to brainstorm ideas and manage them in an order and finally write a text, it allows writers to clarify their thinking in the process of constructing texts but here in the current study, they are used to extract the framework and main points and ideas of a written text.

The genres which were covered in the treatment sessions contained: descriptive, narrative, process, comparison and contrast, classification, definition, cause-effect paragraphs. These seven paragraph types are the most commonly used genres that are covered in most written texts. (Smalley \& Ruetten\& Kozyrev, 2000; Meyers, 2006; Ruetten \& Pavlik, 2012). 
The first half time of every session was dedicated to teaching a specific paragraph structure rule. Firstly, every kind of paragraph was presented to the learners with the commonly used graphic organizer of that type. The teacher introduced the signal words and phrases that identify each text structure and portrayed a graphic organizer for each pattern. It was modeled, explained, demonstrated, and thought aloud by the teacher. It means that, a printed sample of the paragraph genre was given to the learners and the graphic organizer of that sample was drawn by the teacher on the board as a model for the learners. The order of teaching each strategy and genre is presented in 'Table 2'.

The Second half time of the class devoted to teaching common reading strategies as what is being taught in the most traditional reading classes and similar to the content which was taught to the control group. This strategy was explained and practiced on the same printed sample which was a specific paragraph genre.

Afterwards, the teacher gave students opportunities to work on the text. Students practiced the strategies with coaching from the teacher. Another printed sample of that paragraph genre with comprehension questions were given to the learners and teacher asked them to use the newly taught strategies for answering the questions. At this stage, students learned the signal words and phrases in the text that identify each text pattern. They also used graphic organizers to illustrate these patterns. Likewise they tried to connect their knowledge of the paragraph genre with the recently learned reading strategy to answer the questions. It should be mentioned that two sessions were devoted to every writing genre.

It should be mentioned that the instruction for the control group was the reading strategies as what was being taught in the experimental group.

TABLE 2:

OVERVIEW OF THE TEACHING PROCESS FOR EXPERIMENTAL GROUP

\begin{tabular}{|l|l|l|}
\hline Session No. & $\begin{array}{l}\text { First half of the class time } \\
\text { (teaching different paragraph structure rules) }\end{array}$ & $\begin{array}{l}\text { Second half of the class time } \\
\text { (Common reading strategies) }\end{array}$ \\
\hline 1 and 2 & The Structure of Descriptive paragraph & $\begin{array}{l}\text { Strategy One :Activating or Building } \\
\text { Background Knowledge }\end{array}$ \\
\hline 3 and 4 & The Structure of Narrative Paragraph & Strategy Two: Using Sensory Images \\
\hline 5 and 6 & The Structure of the Process Paragraph & Strategy Three: Questioning \\
\hline 7 and 8 & $\begin{array}{l}\text { The Structure of Comparison and Contrast } \\
\text { Paragraph }\end{array}$ & $\begin{array}{l}\text { Strategy Four: Making Predictions and } \\
\text { Inferences }\end{array}$ \\
\hline 9 and 10 & The Structure of Classification Paragraph & Strategy Five: Determining Main Ideas \\
\hline 11 and 12 & The Structure of Definition Paragraph & Strategy Six: Using Fix-Up Options \\
\hline 13 and 14 & The Structure of Cause and Effect Paragraph & Strategy Seven: Synthesizing \\
\hline
\end{tabular}

\section{RESULTS AND DisCUSSIONS}

After finishing the treatment process, the post-test of reading were given to both group members and two other sets of scores were gathered. After that, the gain scores which were subtracting every participant's pre-test score from his/her post-test score were calculated, therefore; two sets of gain scores obtained.

Because of the nature of the current research question, the type of data and the number of variables and groups, T-test was chosen as a test of comparing means between these two groups (control and experimental group). And also the normality of the gain scores of both groups was checked and confirmed by running 'Kolmogorov-Smirnov' test of normality before running the T-test. After running the Independent Sample T-test for gain scores of the control and experimental groups the following Table (Table 3) was reported by SPSS software.

TABLE 3:

COMPARING GAIN SCORES OF THE CONTROL AND EXPERIMENTAL GROUPS BY INDEPENDENT SAMPLE T-TEST

\begin{tabular}{|l|l|l|l|l|l|l|}
\hline Groups & Number & Mean & Std & Mean Difference & T & Sig. (2-tailed) \\
\hline $\begin{array}{l}\text { Gain Score Control } \\
\text { Experimental }\end{array}$ & 30 & 4.3667 & 1.27261 & -7.63333 & -18.572 & .000 \\
\cline { 2 - 4 } & 30 & 12.0000 & 1.85695 & & & \\
\hline
\end{tabular}

Looking at the "Sig. (2-tailed)" column which is '.000' and less than ".05", it can be inferred that there is a statistically significant difference in the mean scores for the two groups and the null hypothesis is strongly rejected. Now the mean scores assist us to distinguish which group performed better at gain scores of reading comprehension test. Since the mean of the experimental group is greater than the mean of control group, therefore; we can deduce that the experimental group gained better scores than the control group in reading comprehension test.

Based on the findings related to the hypothesis, there were statistically significant difference between the gain score results of the experimental group and the gain score results of the control group. The findings indicated that the experimental group predominately benefited from receiving both paragraph structure rules and common reading comprehension strategies as a reading instruction. That is, "teaching paragraph structure rules" appears to be a practicable instructional device for enhancing reading comprehension.

These findings are supported by the outcomes reported by other studies. This finding is specifically in line with what Culp and Spann (1987) had found in their study in university of south Alabama which instructed the use of writing components for the experimental group and also assigned weekly writing tasks to them and finally the results of their 
study indicated that writing has a positive influence on reading. As Flynn and Stainthorp (2006) noted in their study, reading and writing are two sides of a coin and developing reading is impossible without reference to writing.

\section{CONCLUSIONS AND IMPLICATIONS}

As the results of the present research revealed, students who received paragraph structure rules as a reading strategy during the treatment process achieved higher means in their reading gain scores than students of the control group who just received common reading strategies. Therefore, the identification and use of text arrangement are crucial procedures underlying reading comprehension. According to Meyer (1985), familiarity with the perception of the rhetorical relationship of the ideas such as main idea, major ideas, and supporting details can guide readers in comprehending expository texts.

Structural elements in various kinds of paragraphs differ; therefore, it is important to present students to the components of various paragraph structure rules throughout the language instruction. The ability to distinguish and analyze these text structures in different paragraph genres helps readers to comprehend the text more easily. According to Akhondi, Malayeri, \& Samad (2011)" text features can help readers locate and organize information in the text. For example, headings help introduce students to specific bits of information" (Para 8). It is also a crucial strategy to teach and model the position of these components in reading classes. The structure or organization of the text is the arrangement of ideas and the relationships among them which provides a plan for readers. According to Meyer, Brandt, and Bluth (1980) readers who are unfamiliar with text organization are at a disadvantage because they do not have an approach in planning the reading texts.

This study concluded that comprehension as the main factor in reading is enhanced by mixing writing and reading sessions together. It will be practical to integrate reading and writing courses together in a way that every session of instruction should be devoted first to teaching a specific writing genre and then comprehending that text type by employing different reading strategies. Students feel comfort with the previously experienced paragraph genres and will master the comprehension of those paragraph types with more relief.

This study has several implications for materials developers and syllabus designers, teachers of English as a foreign language, and learners.

1. One of the most efficient reading strategies is teaching various paragraph structures or genres to the learner to ease their comprehension of different paragraph structure. Authors of different types of texts use genre structures to organize and link thoughts. Students who realize the theme of text structure and how to analyze it are probable to discover the ideas behind the texts more than students who miss this knowledge.

2. Reading teachers may discover teaching different paragraph structure rules as an efficient method to progress the learners reading achievement. They can choose to divide a session into two parts and first teach the writing rules of a specific genre and then train learners how to comprehend this kind of text structure with more ease.

3. Materials Developers and syllabus designers should be aware that reading and writing are two interrelated skills and if they taught in a connected way they would have more effect on learners' reading improvement. They should design textbooks in a way that to embed both reading and writing instructions together in every teaching session.

4. Writers should consider that the readers have definite expectations about what a text is like, that is a part of a genre; therefore, writer should try to pursue these principles to help readers in conveying the message in their texts.

\section{REFERENCES}

[1] Akhondi, M., \& Malayeri, F. A., \& Samad, A. A. (2011). How to teach expository text facilitate reading comprehension. Retrieved November 13, 2012, from http://www.readingrockets.org/article/52251/.

[2] Berkenkotter, C., \& Huckin, T. N. (1995). Genre knowledge in disciplinary communication: cognition/culture/ power. Hillsdale, NJ: Lawrence Erlbaum Associates.

[3] Brown, A. L., Day, J.D. \& Jones, R.S. (1983). “The development of plans for summarizing texts.”Child Development, 54, 968-979.

[4] Carrell, P.L. (1989). "Metacognitive awareness and second language reading.” Modern Language Journal, 73, 120-133.

[5] Cochrane, V. (2010). Top level structure: Why use graphic organizers to scaffold developing writers? Practically Primary, 15 (3), 34-37.

[6] Culp, M. B. \& Spann, S. (1987). The influence of writing on reading. The Journal of Teaching Writing, 20, 284-289. Retrieved December 1, 2012 from http://journals.iupui.edu/index.php/teachingwriting/article/viewFile/769/741.

[7] Flynn, N, \& Stainthorp, R. (2006). The Learning and Teaching of Reading and Writing. West Sussex England: Whurr Publishers Limited (Wiley).

[8] Fowler, W. S., \& Coe, N. (1978). Nelson quick check placement tests. Sunbury-on-Thames: Nelson.

[9] Gee, J.P. (2008). Social Linguistics and Literacies: ideology in discourses. New York: Roultedge.

[10] Gledhill, C. (1995). Collocation and genre analysis: the phraseology of grammatical items in cancer research abstracts and articles. Zeitschrift für Anglistik und Amerikanistik ,43, 11-29.

[11] Goen, S., \& Tropp, H.G. (2003) Integrating reading and writing: a response to the basic writing crisis. Journal of Basic Writing. 22(2), 90-113. Retrieved December 1, 2012 from http://wac.colostate.edu/jbw/v22n2/goen.pdf.

[12] Grabe, W., \& Stoller, F.L. (2002). Teaching and researching reading. Harlow: Pearson Education.

[13] Grabe, W. (2009). Reading in a second language: Moving from theory to practice. Cambridge: Cambridge university press. 
[14] Graham, S., \& Hebert, M.A. (2010). Writing to read: Evidence for how writing can improve reading. A Carnegie Corporation Time to Act Report. Washington, DC: Alliance for Excellent Education.

[15] Harmer, J. (2007). How to teach English. England: Longman Pearson.

[16] Harwood, N. (2002). Taking a lexical approach to teaching: principles and problems. International Journal of Applied Linguistics .12(2): 139-155.

[17] Hyland, K. (2004). Genre and second language writing. Chicago, IL: University of Michigan Press.

[18] Levin, J.R., \& Pressley, M. (1981). Improving children's prose comprehension: Selected strategies that seem to succeed. In C.M. Santa \& B.L. Hayes (Eds.), Children's prose comprehension: Research and practice (pp. 44-71).Newark, DE: International Reading Association.

[19] Livingstone, S.M. (1994). The rise and fall of audience research: an old story with a new ending. In Mark R Levy \& Michael Gurevitch (Eds.) Defining Media Studies: Reflections on the Future of the Field. New York: Oxford University Press, pp. 24754.

[20] Meyer, J.B.F., Brandt, D.M., \& Bluth, G.J. (1980). Use of top-level structure in text: Key for reading comprehension of ninth grade students. Reading Research Quarterly, 16(1), 72-103.

[21] Meyer, J.B.F. (1985). Prose analysis: Purposes, procedures, and problems. In B.K. Britten \& J.B. Black (Eds.), Understanding expository text: A theoretical and practical handbook for analyzing explanatory text (pp. 11-64). Hillsdale, NJ: Erlbaum.

[22] Meyers, A. (2006).Composing with Confidence: Writing Effective Paragraph and Essays. New York: Longman Pearson.

[23] Moreillon, J. (2007). Collaborative Strategies for Teaching Reading Comprehension: maximizing your impact. Chicago: American Library Association.

[24] Nation, I.S.P. (2009). Teaching ESL/EFL reading and writing. New York: Routledge.

[25] Rosenblatt, L.M. (1988). Writing and Reading: The Transactional Theory .In J. Mason (Ed.), Reading and Writing Connection. Newton, MA: Allyn and Bacon.

[26] Ruetten, M.K., Pavlik, C. (2012). Developing composition skills: Academic writing and Grammar, Third edition. Boston: Heinle \& Heinle.

[27] Smalley,R.L., \& Ruetten,M.K., \& Kozyrev, J, R. (2000). Refining composition skills: Rhetoric and grammar. Boston: Heinle \& Heinle.

[28] Thaole.T. (2011). The importance of reading on teaching and learning. Retrieved November 13, 2012, from http://www.slideshare.net/thanhthaole/the-importance-of-reading-on-teaching-and-learning.

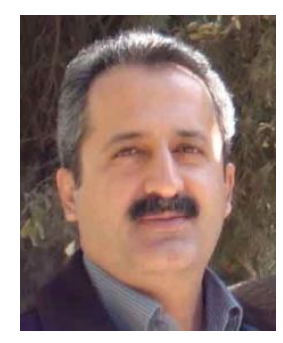

Amir Marzban is an assistant professor of TESOL at Islamic Azad University, Qaemshahr branch. His research interests include conversation analysis, L2 reading \& writing, CALL, and teacher education. He has published in both Iranian and International journals and also has presented in many international conferences.

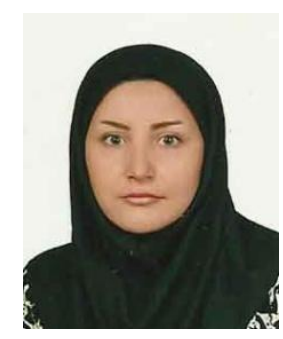

Azadeh Adibi is an English teacher with M.A degree in TEFL. She received her M.A from Islamic Azad University, Mazandaran Science and Research Branch. She has taught English in High school and language institutes. She received her B.A in English Language Teaching from Islamic Azad University, Tehran South Branch. Her main research interests are English language teaching with the focus on literacy skills, testing and statistics, team work, and automaticity. 